\title{
Energy and Exergy Based Optimization of Licl-Water Absorption Cooling System
}

\author{
Bhargav Pandya ${ }^{1 *}$, Jatin Patel $^{2}$, Vinay Kumar ${ }^{1}$, Vijay Matawala ${ }^{1}$ \\ ${ }^{1}$ Department of Mechanical Engineering, Gujarat Power Engineering and Research Institute, Gujarat, India \\ ${ }^{2}$ Department of Mechanical Engineering, School of Technology, Pandit Deendayal Petroleum University, Gujarat, India
}

*Corresponding Author: bhargavmechatherm@gmail.com

Citation: Pandya, B., Patel, J., Kumar, V. and Matawala, V. (2017). Energy and Exergy Based Optimization of Licl-Water Absorption Cooling System. European Journal of Sustainable Development Research, 1(2), 08. doi: $10.20897 /$ ejosdr.201708

Published: June 15, 2017

\section{ABSTRACT}

\begin{abstract}
This study presents thermodynamic analysis and optimization of single effect LiCl- $\mathrm{H}_{2} \mathrm{O}$ absorption cooling system. Thermodynamic models are employed in engineering equation solver to compute the optimum performance parameters. In this study, cut off temperature to operate system has been obtained at various operating temperatures. Analysis depicts that on 3.59\% rise in evaporator temperature, the required cut-off temperature decreased by $12.51 \%$. By realistic comparison between thermodynamic first and second law analysis, optimum generator temperature relative to energy and exergy based prospective has been evaluated. It is found that optimum generator temperature is strong function of evaporator and condenser temperature. Thus, it is feasible to find out optimum generator temperature for various combinations of evaporator and condenser temperatures. Contour plots of optimum generator temperature for several combinations of condenser and absorber temperatures have been also depicted.
\end{abstract}

Keywords: LiCl- $\mathrm{H}_{2} \mathrm{O}, \mathrm{COP}$, Exergy, Optimization, Generator temperature

\begin{tabular}{|c|c|c|c|}
\hline \multicolumn{4}{|c|}{ Nomenclature } \\
\hline COP & coefficient of performance & \multicolumn{2}{|l|}{ Subscripts } \\
\hline & & $A$ & Absorber \\
\hline$e$ & Specific exergy (kJ/kg) & $C$ & Condenser \\
\hline$h$ & specific enthalpy $(\mathrm{kJ} / \mathrm{kg})$ & $E$ & Evaporator \\
\hline$\dot{m}$ & mass flow rate $(\mathrm{kg} / \mathrm{s})$ & $G$ & Generator \\
\hline$\dot{Q}$ & heat load $(\mathrm{kW})$ & in & inlet stream \\
\hline$s$ & specific entropy $(\mathrm{kJ} / \mathrm{kg} \mathrm{K})$ & $\min$ & Minimum \\
\hline$T$ & temperature $(\mathrm{K})$ & out & outlet stream \\
\hline$P$ & pressure $(\mathrm{kPa})$ & $o$ & dead state (ambient) \\
\hline$\dot{W}$ & mechanical work (kW) & $P$ & Pump \\
\hline$X$ & concentration of $\mathrm{LiCl}$ & $r$ & Refrigerant \\
\hline \multicolumn{2}{|c|}{ Greek symbols } & $R E X P$ & refrigerant expansion valve \\
\hline$\eta$ & efficiency & $S E X P$ & solution expansion valve \\
\hline$\rho$ & density $(\mathrm{kg} / \mathrm{m} 3)$ & $S H X$ & solution heat exchanger \\
\hline \multirow[t]{3}{*}{$\Delta \dot{\psi}$} & exergy destruction rate $(\mathrm{kW})$ & $s S$ & strong solution \\
\hline & & sys & System \\
\hline & & $w s$ & weak solution \\
\hline
\end{tabular}




\section{INTRODUCTION}

A recent analysis shows that global warming and depletion of ozone layer is continuously increasing because of conventional referigerants (Bolazi and Huan 2013). According to United Nations study, Chloro-flouro carbons (CFC) and Hydro-chlorofloro carbon (HCFC) fluids which are widely used in conventional compression chiller are mainly responsible for ozone layer depletion (Wu and Eames 2000). The ban on this type of CFC based chemicals forced to develop environmental friendly refrigeration technologies and new refrigerant. Vapour absorption refrigeration system (VARS) is the optimum alternative for vapour compression chiller. VARS can also utilize non-conventional energy i.e. solar energy, biomass, geothermal energy etc. (Kaynakli and Yamankaradeniz 2007). Performance of VARS is mainly depended upon the type of working pair has been chosen. There are many pairs available for VARS, but generally used pairs are $\mathrm{LiBr}-\mathrm{H}_{2} \mathrm{O}$ and $\mathrm{NH}_{3}-\mathrm{H}_{2} \mathrm{O}$ [Srikhirin et al. 2001]. $\mathrm{NH}_{3}-\mathrm{H}_{2} \mathrm{O}$ absorption system is more complicated as it requires separate rectifier mechanism to remove water vapour from refrigerant vapour, whereas main problem occurs in $\mathrm{LiBr}-\mathrm{H}_{2} \mathrm{O}$ system is the crystallization [Srikhirin et al. 2001]. Gommed et al. (2004) concluded that $\mathrm{LiCl}-\mathrm{H}_{2} \mathrm{O}$ pair is one of the good options for VARS working fluid pair as it has advantages of triple state point (solid, liquid and vapour form), long term stability in regeneration process under atmospheric condition and cost as compared to LiBr- $\mathrm{H}_{2} \mathrm{O}$. Won and Lee (1991) carried out study for thermodynamic design data for double effect $\mathrm{LiCl}-\mathrm{H}_{2} \mathrm{O}$ absorption system and comparison for the performance of $\mathrm{LiCl}-\mathrm{H}_{2} \mathrm{O}$ and $\mathrm{LiBr}-\mathrm{H}_{2} \mathrm{O}$ absorption system and it is found that COP with $\mathrm{LiCl}-\mathrm{H}_{2} \mathrm{O}$ is better than that of $\mathrm{LiBr}-$ $\mathrm{H}_{2} \mathrm{O}$ system. Saravanan and Maiya (1998) found that minimum generator temperature required to operate the LiCl$\mathrm{H}_{2} \mathrm{O}$ VARS is lower corresponding to $\mathrm{LiBr}-\mathrm{H}_{2} \mathrm{O}$ VARS. Crystallization is the major issue in any salt based aqueous solution, so to prevent this phenomenon $\mathrm{LiCl}-\mathrm{H}_{2} \mathrm{O}$ pair operator has to choose operating parameters in optimistic range. Grover et al. (1988) carried out feasible range for each operating parameters and possible combination of operating temperature for $\mathrm{LiCl}-\mathrm{H}_{2} \mathrm{O}$ system has been also evaluated. El-Ghalban (2002) conducted experimental investigation of intermittent $\mathrm{LiCl}-\mathrm{H}_{2} \mathrm{O}$ absorption cycle and it is found that that $\mathrm{LiCl}-\mathrm{H}_{2} \mathrm{O}$ system can operate with low temperature heat source. Second law based thermodynamic analysis of $\mathrm{LiCl}$-Water system was also performed earlier. Gunhan et al. (2014) evaluated experimental and exergetic performance of solar assisted $\mathrm{LiCl}-\mathrm{H}_{2} \mathrm{O}$ and concluded that exergetic efficiency of the system varied between 13.1 to 43.2\%. Gogoi and Konwar (2016) observed that irreversibility of system increases with evaporator, condenser and absorber temperature and concluded that total exergy destruction of $\mathrm{LiCl}-\mathrm{H}_{2} \mathrm{O}$ is lower compared to that of $\mathrm{LiBr}-\mathrm{H}_{2} \mathrm{O}$ VARS. There are many literatures (Gebreslassie et al. 2012, Rubio-Maya et al. 2012, Marcos et al. 2011, Arora and Kaushik 2009) available for optimization of $\mathrm{LiBr}-\mathrm{H}_{2} \mathrm{O}$ VARS. Samanta and Basu (2016) carried out realistic comparison between two approaches of thermodynamics and optimum generator temperature corresponding to first and second law perspectives also have been evaluated for $\mathrm{LiBr}-\mathrm{H}_{2} \mathrm{O}$ VARS. Main method of improving efficiency of absorption cycle is through thermodynamic analysis and optimization. As far as $\mathrm{LiCl}-\mathrm{H}_{2} \mathrm{O}$ VARS is concern, thermodynamic optimization corresponding to energy and exergy based perspectives neither available nor it was attempted before.

Therefore, in this present study first law and second law based analysis has been adopted to optimize the system performance. In this work, main focus is on recognition of optimum generator temperature for both the energy and exergy perspective. System COP and exergy destruction rate are selected as objective parameters and influence of evaporator and condenser temperature upon optimum generator temperature has been also evaluated.

\section{SYSTEM DESCRIPTION}

Vapour absorption refrigeration system with $\mathrm{LiCl}-\mathrm{H}_{2} \mathrm{O}$ as working fluid in the schematic diagram is shown in Figure 1. Whole system consists of main equipments as generator, condenser, absorber and evaporator with auxiliary parts like solution heat exchanger, valves and solution pump. As shown in Figure 1, at absorber outlet (1) pump forces the strong solution at low pressure in absorber through a SHX to the generator at high pressure (3). The generator by absorbing the low grade heat from any source like solar energy, waste heat and geothermal energy divides the $\mathrm{LiCl}-\mathrm{H}_{2} \mathrm{O}$ solution and vaporises the $\mathrm{H}_{2} \mathrm{O}$. The temperature of the weak solution in the SHX increases and that of strong solution decreases. The vapour of $\mathrm{H}_{2} \mathrm{O}$ refrigerant (7) flows towards the condenser, where the refrigerant gets condensed. The condensed refrigerant (8) flows through expansion valve to the evaporator (3). Here, heat is absorbed by the refrigerant from the evaporator load. Therefore, refrigerant gets evaporated which subsequently enters to the absorber (10). At the generator exit (4), high pressure weak solution enters to the SHX where it rejects the heat. In the absorber, weak solution absorbs refrigerant vapour from the evaporator. 


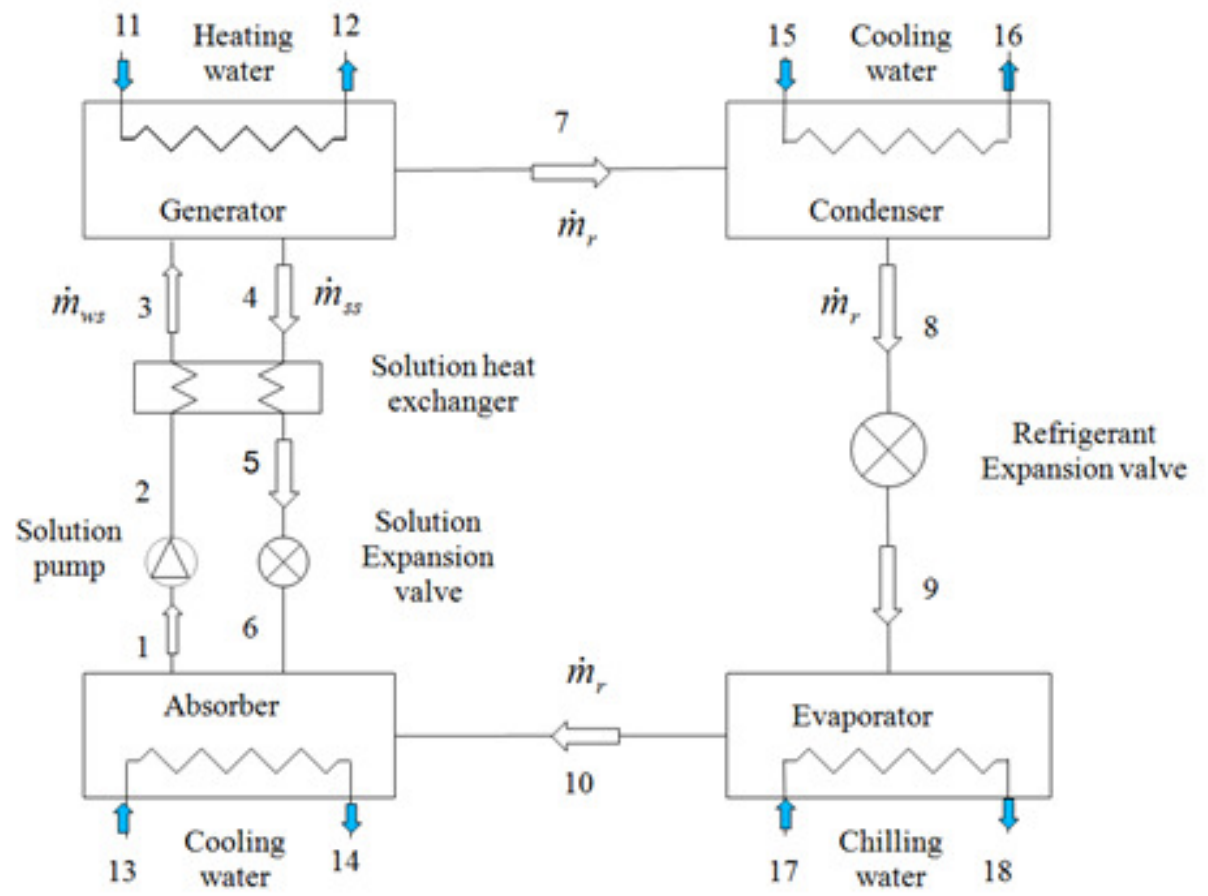

Figure 1. Schematic of $\mathrm{LiCL}-\mathrm{H}_{2} \mathrm{O}$ absorption refrigeration system.

\section{THERMODYNAMIC FORMULATION}

The main purpose of thermodynamic analysis is to identify the system flaws and suggests possible areas of thermodynamic losses and proposes the methods of improving the system performance. COP is calculated from first law and second law analysis provided the exergy destruction of every device. To simplify the thermodynamic modelling of system, several assumptions are made as follows (1) Absorption system is analysed under steady state situations (2) Along the working fluid flow, pressure drop and heat losses/gains to the ambient are negligible. (3) Refrigerant condensed inside condenser and leaves as saturated liquid and exits the evaporator as dry saturated vapour. (4) Expansion valves are insulated, therefore isenthalpic.

Mass balance equation at generator can be written as

$\sum \dot{m}_{\text {in }}=\sum \dot{m}_{\text {out }}$

$\sum(m X)_{\text {in }}=\sum(m X)_{\text {out }}$

Energy balance formulation for each component can be written as

$$
\begin{aligned}
& \dot{Q}_{G}=\dot{m}_{r} h_{7}+\dot{m}_{s s} h_{4}-\dot{m}_{w s} h_{3}=\dot{m}_{G}\left(h_{11}-h_{12}\right) \\
& \dot{Q}_{A}=\dot{m}_{r} h_{10}+\dot{m}_{s s} h_{6}-\dot{m}_{w s} h_{1}=\dot{m}_{A}\left(h_{14}-h_{13}\right) \\
& \dot{Q}_{C}=\dot{m}_{r}\left(h_{7}-h_{8}\right)=\dot{m}_{C}\left(h_{16}-h_{15}\right) \\
& \dot{Q}_{E}=\dot{m}_{r}\left(h_{10}-h_{9}\right)=\dot{m}_{E}\left(h_{17}-h_{18}\right) \\
& \dot{Q}_{S H X}=\dot{m}_{w s}\left(h_{3}-h_{2}\right)=\dot{m}_{s s}\left(h_{5}-h_{6}\right) \\
& \dot{W}_{P}=\frac{\dot{m}_{w s}\left(P_{C}-P_{E}\right)}{\rho \eta_{P}}
\end{aligned}
$$




$$
C O P=\frac{\dot{Q}_{E}}{\dot{Q}_{G}+\dot{W}_{P}}
$$

Exergy is the measure of maximum useful work that can be obtained from the reversible system in a specific environment. The exergy evaluation is based on temperature, pressure and constitution of stream as the system goes through a given state to an environmental state. Here the chief purpose of exergy analysis is to find out the inefficiencies and irreversibility's in energy system to optimum the parameters. The physical exergy, which is dependent with working temperature and pressure, is defined as the maximum work output from working state to environmental state, and exergy of pure substance is given by (Çengel and Boles, 2015).

$$
e=\left(h-h_{o}\right)-T_{o}\left(s-s_{o}\right)
$$

Exergy destruction rate under a steady flow process can be written as (Çengel and Boles , 2015).

$$
\Delta \dot{\psi}_{\text {destyoyed }}=\sum \dot{m}_{\text {in }} e_{\text {in }}-\sum \dot{m}_{\text {out }} e_{\text {out }}-\left[\sum \dot{Q}\left(1-\frac{T_{0}}{T}\right)\right] \pm \dot{W}
$$

In equation 11, first two terms indicate the sum of the exergy rate of input and output fluid stream flow while the third term indicates the exergy related with heat transfer take place in control volume and fourth term indicate the mechanical work transfer to or from the system. In fourth term, take positive sign when work is transfer to the system and negative sign when work is transfer from system.

In all previous performed exergy studies of LiCl-Water VARS only physical exergy has been considered while chemical, potential and kinetic exergies have been neglected (Gogoi and Konwar 2016, Gunhan et al. 2014). Therefore, this analysis only physical exergy of $\mathrm{LiCl}$-water solution is considered. Chemical, kinetic and potential exergy has been neglected. Owing to the fact that exergy balances the dead state values get cancelled [PalaciosBereche et al. 2012] therefore, exergy balance formulation for each component can be written as

$$
\begin{aligned}
& \Delta \dot{\psi}_{G}=\dot{m}_{w s}\left(h_{3}-T_{o} s_{3}\right)+\dot{m}_{s s}\left(h_{4}-T_{o} s_{4}\right)-\dot{m}_{r}\left(h_{7}-T_{o} s_{7}\right)+\dot{m}_{G}\left(\left(h_{11}-T_{o} s_{11}\right)-\left(h_{12}-T_{o} s_{12}\right)\right) \\
& \Delta \dot{\psi}_{A}=\dot{m}_{r}\left(h_{10}-T_{o} s_{10}\right)+\dot{m}_{s s}\left(h_{6}-T_{o} s_{6}\right)-\dot{m}_{w s}\left(h_{1}-T_{o} s_{1}\right)+\dot{m}_{A}\left(\left(h_{13}-T_{o} s_{13}\right)-\left(h_{14}-T_{o} s_{14}\right)\right) \\
& \Delta \dot{\psi}_{E}=\dot{m}_{r}\left(h_{9}-T_{o} s_{9}\right)-\dot{m}_{r}\left(h_{10}-T_{o} s_{10}\right)+\dot{m}_{E}\left(\left(h_{17}-T_{o} s_{17}\right)-\left(h_{18}-T_{o} s_{18}\right)\right) \\
& \Delta \dot{\psi}_{C}=\dot{m}_{r}\left(h_{7}-T_{o} s_{7}\right)-\dot{m}_{r}\left(h_{8}-T_{o} s_{8}\right)+\dot{m}_{C}\left(\left(h_{15}-T_{o} s_{15}\right)-\left(h_{16}-T_{o} s_{16}\right)\right) \\
& \Delta \dot{\psi}_{S H X}=\dot{m}_{w s}\left(h_{2}-h_{3}-T_{o}\left(s_{2}-s_{3}\right)\right)+\dot{m}_{w s}\left(h_{4}-h_{5}-T_{o}\left(s_{4}-s_{5}\right)\right) \\
& \Delta \dot{\psi}_{P}=\dot{m}_{w s}\left(h_{1}-h_{2}-T_{o}\left(s_{1}-s_{2}\right)\right)+\dot{W}_{P} \\
& \Delta \dot{\psi}_{R E X P}=\dot{m}_{r}\left(h_{8}-h_{9}-T_{o}\left(s_{8}-s_{9}\right)\right) \\
& \Delta \dot{\psi}_{S E X P}=\dot{m}_{s S}\left(h_{5}-h_{6}-T_{o}\left(s_{5}-s_{6}\right)\right)
\end{aligned}
$$

Together the exergy of a material stream can be expressed by the following equation.

$$
\Delta \dot{\psi}_{\text {sys }}=\Delta \dot{\psi}_{G}+\Delta \dot{\psi}_{A}+\Delta \dot{\psi}_{E}+\Delta \dot{\psi}_{C}+\Delta \dot{\psi}_{S H X}+\Delta \dot{\psi}_{R E X P}+\Delta \dot{\psi}_{S E X P}+\Delta \dot{\psi}_{P}
$$

\section{RESULT AND DISCUSSION}

A computational code has been developed using engineering equation solver (EES) modeling software to calculate the energy and exergy analysis of system. In present analysis of 1 TR system, effectiveness of SHX and solution pump efficiency considered as 0.7 and $95 \%$ respectively Moreover, standard ambient temperature and pressure conditions $25^{\circ} \mathrm{C}$ and $101.3 \mathrm{kPa}$. Supply of cooling water for both absorber and condenser and steam to generator assumed as $0.4 \mathrm{~kg} / \mathrm{s}$. Mass flow rate of air to evaporator assumed as $0.5 \mathrm{~kg} / \mathrm{s}$. In this analysis supplied steam temperature to the generator is considered as $50{ }^{\circ} \mathrm{C}$ higher than corresponding generator temperature. In 


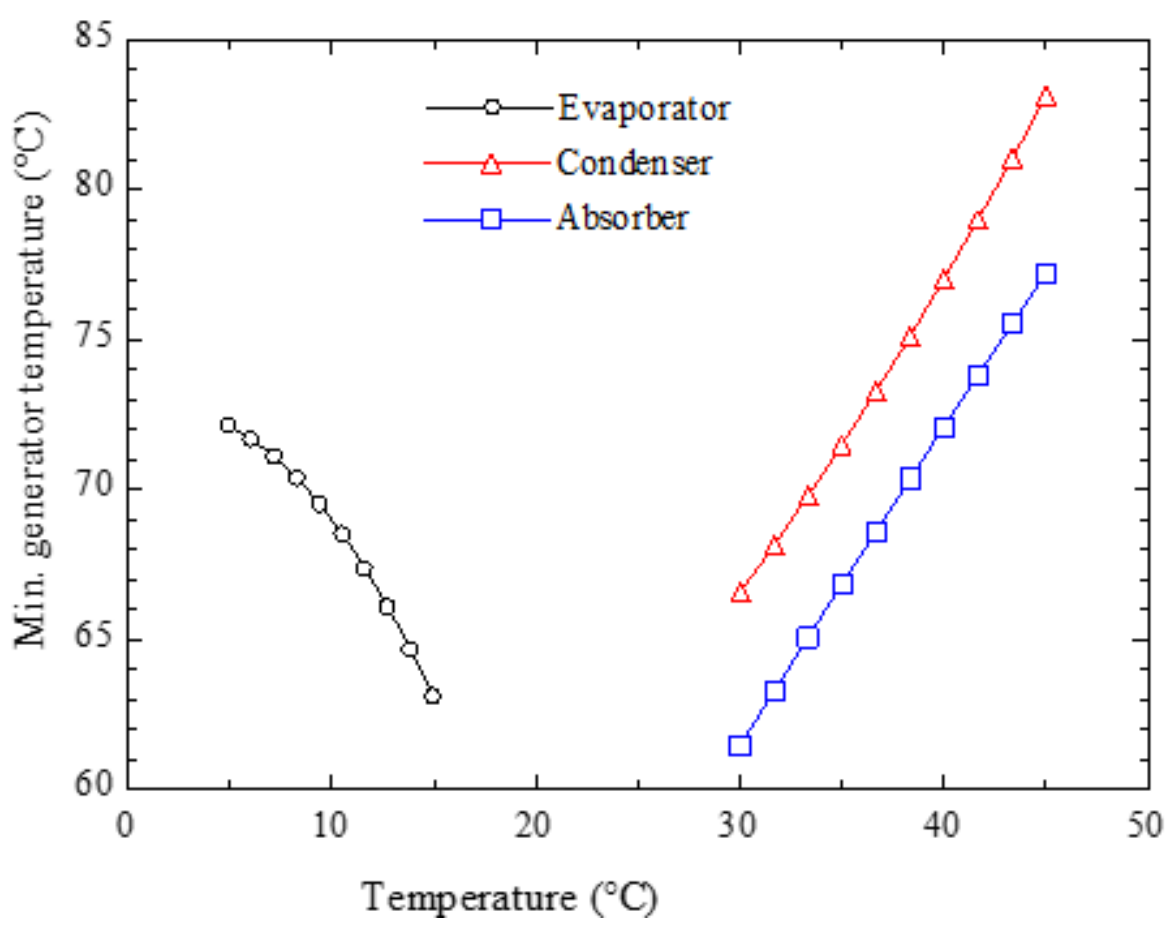

Figure 2. Min. generator temperature against condenser, absorber and evaporator temperatures.

procedure of finding out optimum generator temperature condenser temperature and absorber temperature kept identical in all considered cases.

\section{Cut off temperature}

Cut of temperature can be described as the minimum generator temperature required to run the system. It depends upon of concentration of weak solution and pressure of generator in VARS. Both these parameters depend upon absorber, evaporator and condenser temperatures. (Saravanan and Maiya 1998).

$T_{G, \min }=f\left(P_{G}, X_{w s}\right)$

To correlate the cut off temperature with various absorber, evaporator and condenser temperature, a polynomial equation has been evaluated by regression analysis. The operating range of temperatures for present evaluation is $5^{\circ} \mathrm{C} \leq \mathrm{T}_{\mathrm{E}} \leq 15^{\circ} \mathrm{C}, 30^{\circ} \mathrm{C} \leq \mathrm{T}_{\mathrm{C}} \& \mathrm{~T}_{\mathrm{A}} \leq 45^{\circ} \mathrm{C}$ and for this range only, the proposed correlation used to calculate the cut-off temperature is obtained as:

$$
\begin{aligned}
& T_{G, \min }=3.267+2.296 \times 10^{-1} \cdot T_{C}+1.166 \times 10^{-2} T_{C}^{2} \\
& +1.256 \cdot T_{A}-2.767 \times 10^{-3} T_{A}^{2}+0.2278 \cdot T_{E}+5.649 \times 10^{-2} T_{E}^{2}
\end{aligned}
$$

Effect of condenser, absorber and evaporator temperature on cut-off temperature is illustrated in Figure 2. It is found that cut off temperature decreases from $72^{\circ} \mathrm{C}$ to $63^{\circ} \mathrm{C}$ with increase in evaporator temperature from $5^{\circ} \mathrm{C}$ to $15^{\circ} \mathrm{C}$ since as the evaporator temperature increases, water mass concentration in solution increases and consequently it lowers the cut-off temperature to run the system. It is also found that required cut-off temperature is increased from $61^{\circ} \mathrm{C}$ to $77^{\circ} \mathrm{C}$ and from $66^{\circ} \mathrm{C}$ to $83^{\circ} \mathrm{C}$ with increase in absorber and condenser temperature from $30^{\circ} \mathrm{C}$ to $45^{\circ} \mathrm{C}$ owing to the fact that as the temperature of absorber and condenser increases, $\mathrm{LiCl}$ concentration in solution increases which causes to increases cut off temperature. Results demonstrates that required cut-off temperature is $6^{\circ} \mathrm{C}$ lower for absorber in given temperature range which concludes that the impact of rising condenser temperature on cut off temperature is dominant over increasing absorber temperature.

\section{Maximum generator Temperature}

In $\mathrm{LiCl}-\mathrm{H}_{2} \mathrm{O}$ working pair, thermodynamic property of the solution cannot be determined if the $\mathrm{LiCl}$ concentration exceeds $50 \%$. Therefore, it is necessity to prevent the concentration of $\mathrm{LiCl}$ in strong solution above $50 \%$. Hence, maximum generator temperature must be evaluated for getting the information about highest temperature of generator at which system can perform. This also prevents the problem of crystallization in LiCl$\mathrm{H}_{2} \mathrm{O}$ VARS. Strong solution concentration is a function of generator and condenser temperature. A regression analysis has been carried out to correlate the maximum generator temperature with given condenser temperature. As a part of present study, obtained regression correlation is as follows: 


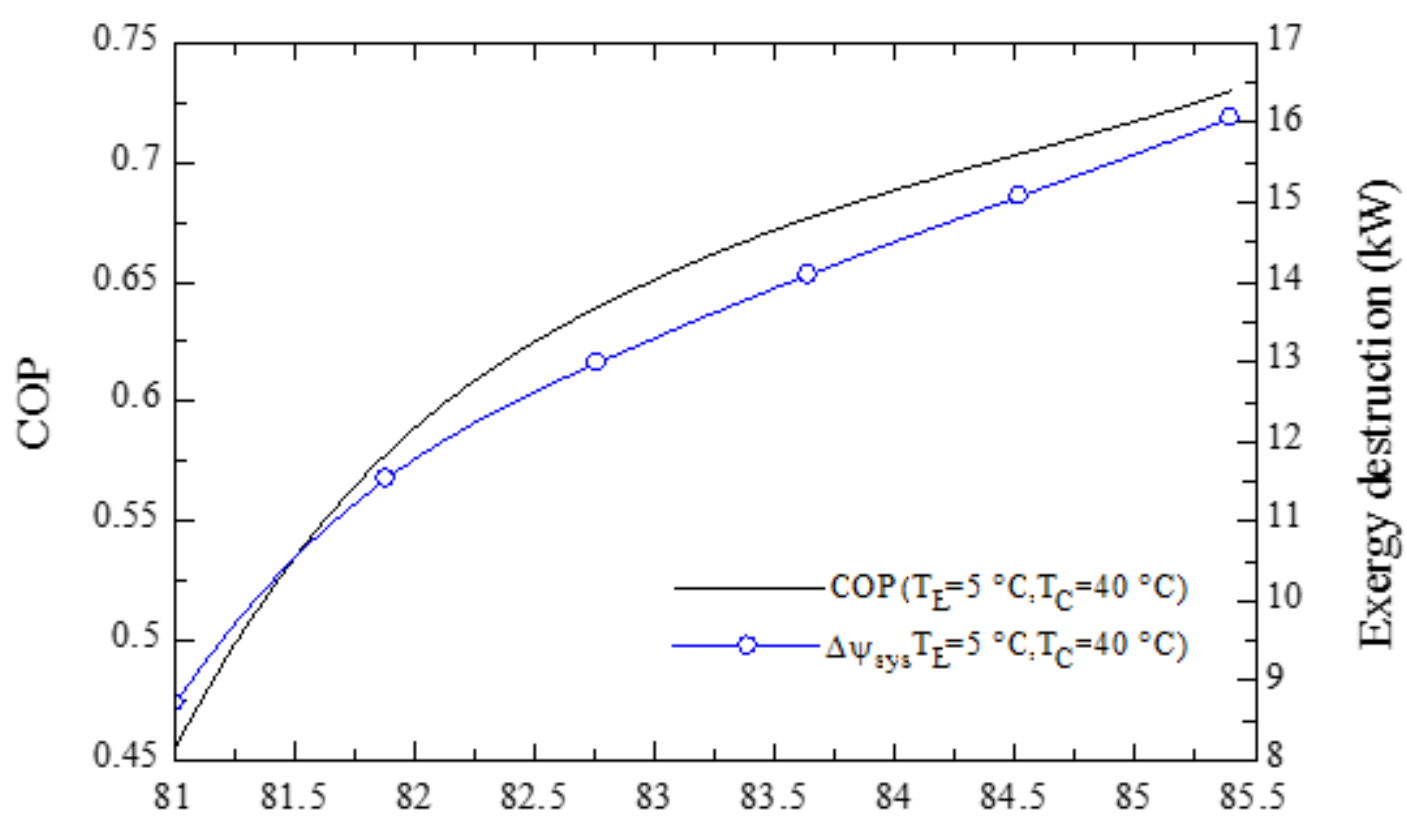

Generator temperature $\left({ }^{\circ} \mathrm{C}\right)$

Figure 3. Effect of generator temperature on COP and total exergy destruction of system at $\mathrm{T}_{\mathrm{E}}=5{ }^{\circ} \mathrm{C}$, $\mathrm{T}_{\mathrm{C}}=\mathrm{T}_{\mathrm{A}}=40^{\circ} \mathrm{C}$.

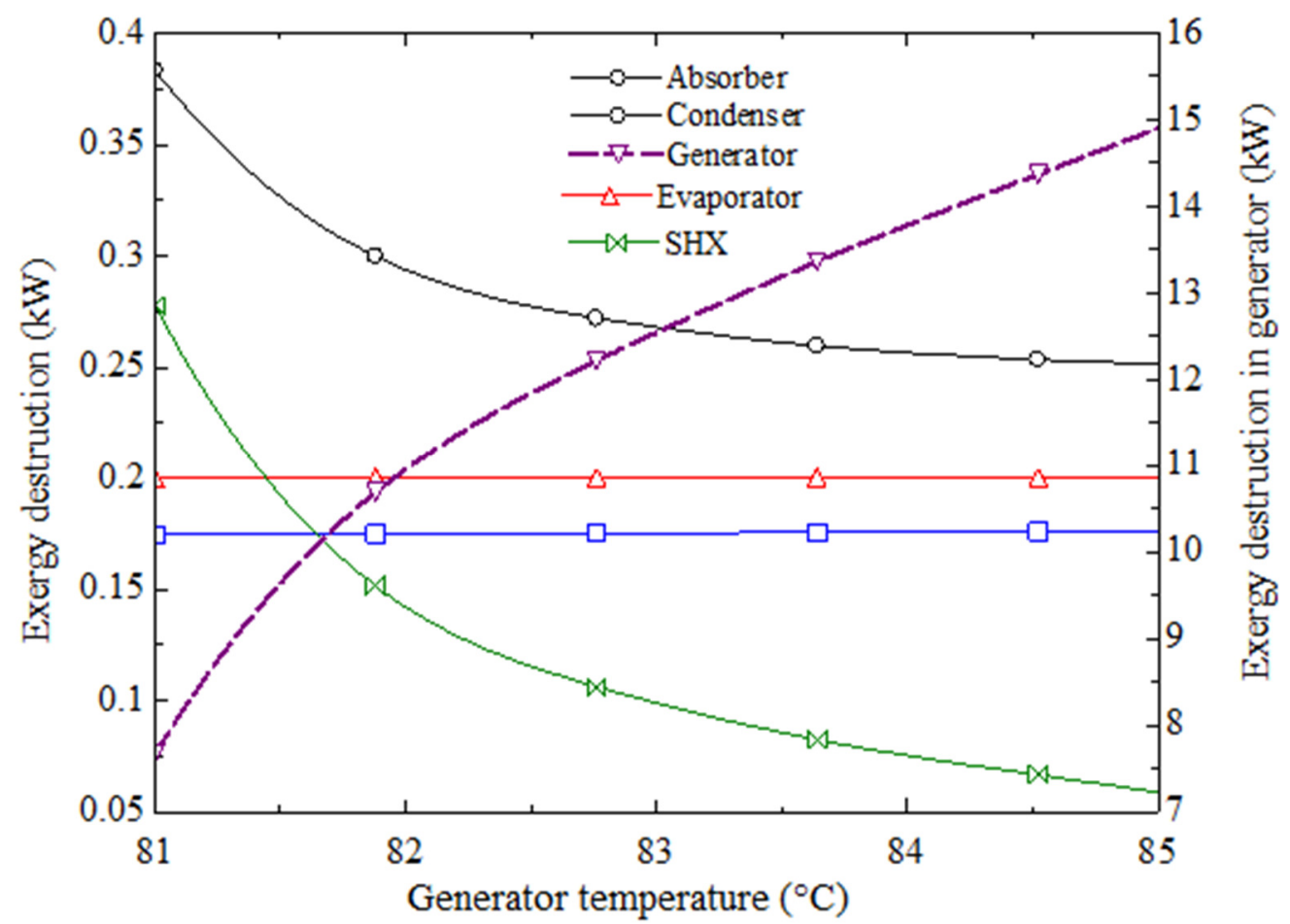

Figure 4. Variation of exergy destruction of various component system with generator temperature.

$$
T_{G, \max }=43.3294+0.88662719 . T_{C}+3.98303 \times 10^{-3} T_{C}^{2}
$$

\section{Effect of Generator Temperature}

Figure 3 represents the effects of generator temperature change on COP and exergy destruction rate of absorption system. In this figure, the considered generator temperature range is $81{ }^{\circ} \mathrm{C}$ to $85.5^{\circ} \mathrm{C}$ because for $\mathrm{T}_{\mathrm{E}}=$ $5^{\circ} \mathrm{C}$ and $\mathrm{T}_{\mathrm{C}}=\mathrm{T}_{\mathrm{A}}=40^{\circ} \mathrm{C}$, the cut off temperature obtained from equation $(22)$ is $81^{\circ} \mathrm{C}$ and beyond $85.5^{\circ} \mathrm{C}$, the concentration of $\mathrm{LiCl}$ increases beyond the $50 \%$ and crystallization starts. It can be seen from Figure 3 that as generator temperature increases, the COP of system increases. The maximum COP obtained for the system is 0.72 


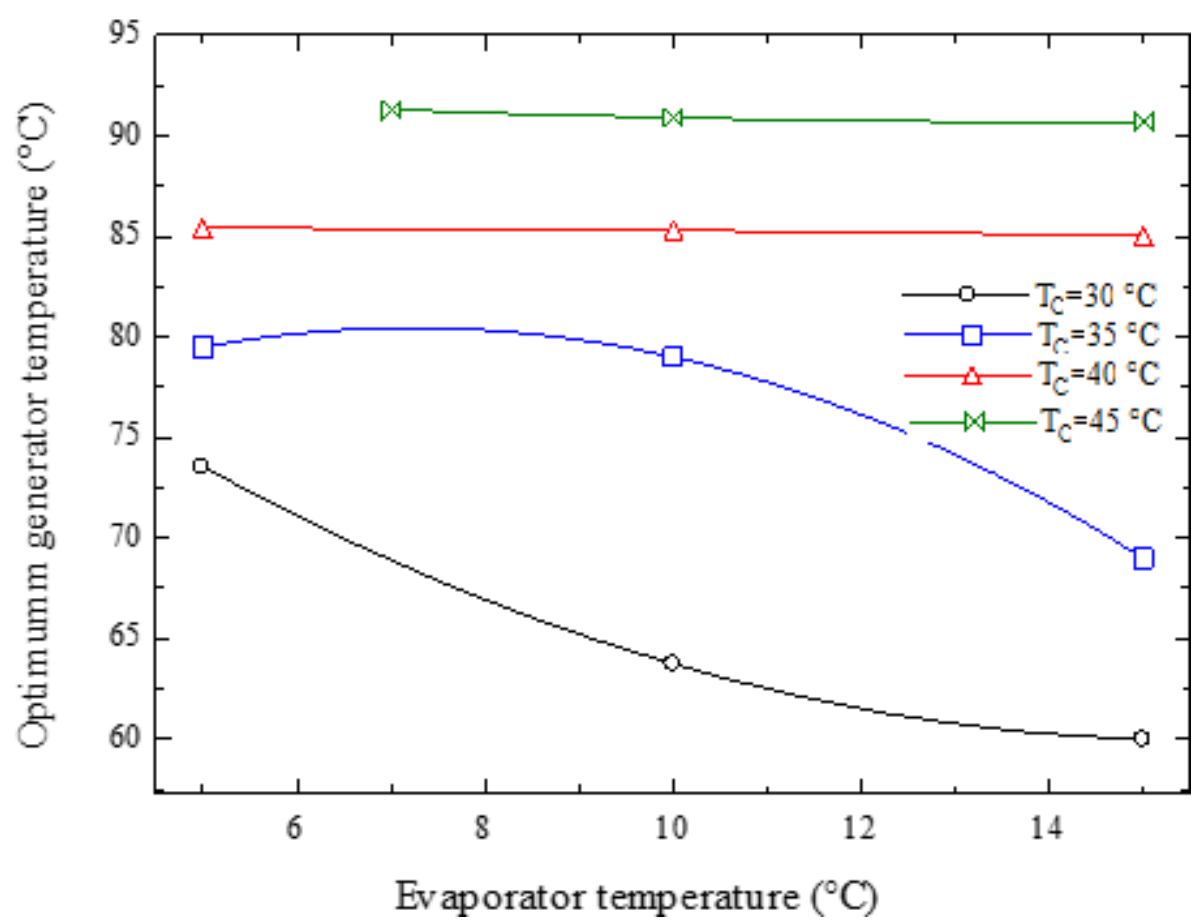

Figure 5. Optimum generator temperature corresponding to maximum COP against evaporator temperature at various condenser temperatures.

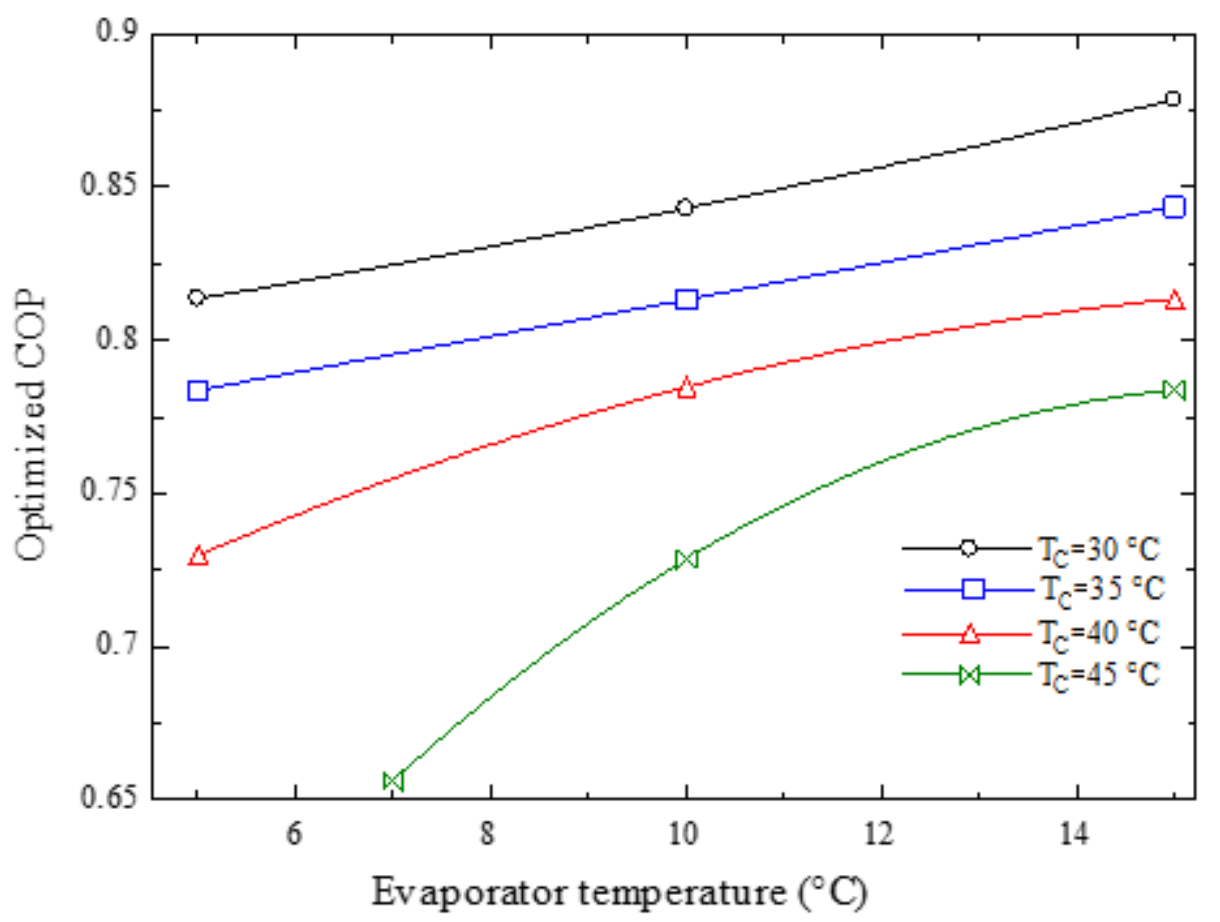

Figure 6. Optimized COP against evaporator temperature at various condenser temperature.

at $85.4{ }^{\circ} \mathrm{C}$ generator temperature and beyond that COP decreases. With increasing generator temperature, mass flow rate of weak and strong solution decreases with generator temperature and refrigerant mass flow rate remain unchanged. It is also figured out that the enthalpy of superheated water increases negligibly with generator temperature however weak and strong solution enthalpy raises significantly causes to decrease heat load in generator. So consequently COP of system increases with generator temperature.

As can be seen from Figure 3, with increase in generator temperature, total exergy destruction rate increases rapidly. Figure 3 also depicts that minimum exergy destruction value of $8.721 \mathrm{~kW}$ is obtained at $81^{\circ} \mathrm{C}$. Figure 4 represents exergy destruction in various components of system with respect to considered generator temperature range. In Figure, the right vertical axis represents the exergy destruction in generator while left vertical axis represents the exergy destruction in rest of the components of given system. It is observed from Figure 4 that with increasing generator temperature, exergy destruction in condenser increases marginally and in generator increases significantly. While in SHX and absorber exergy destruction decreases. From Figure 3 it is remarked 


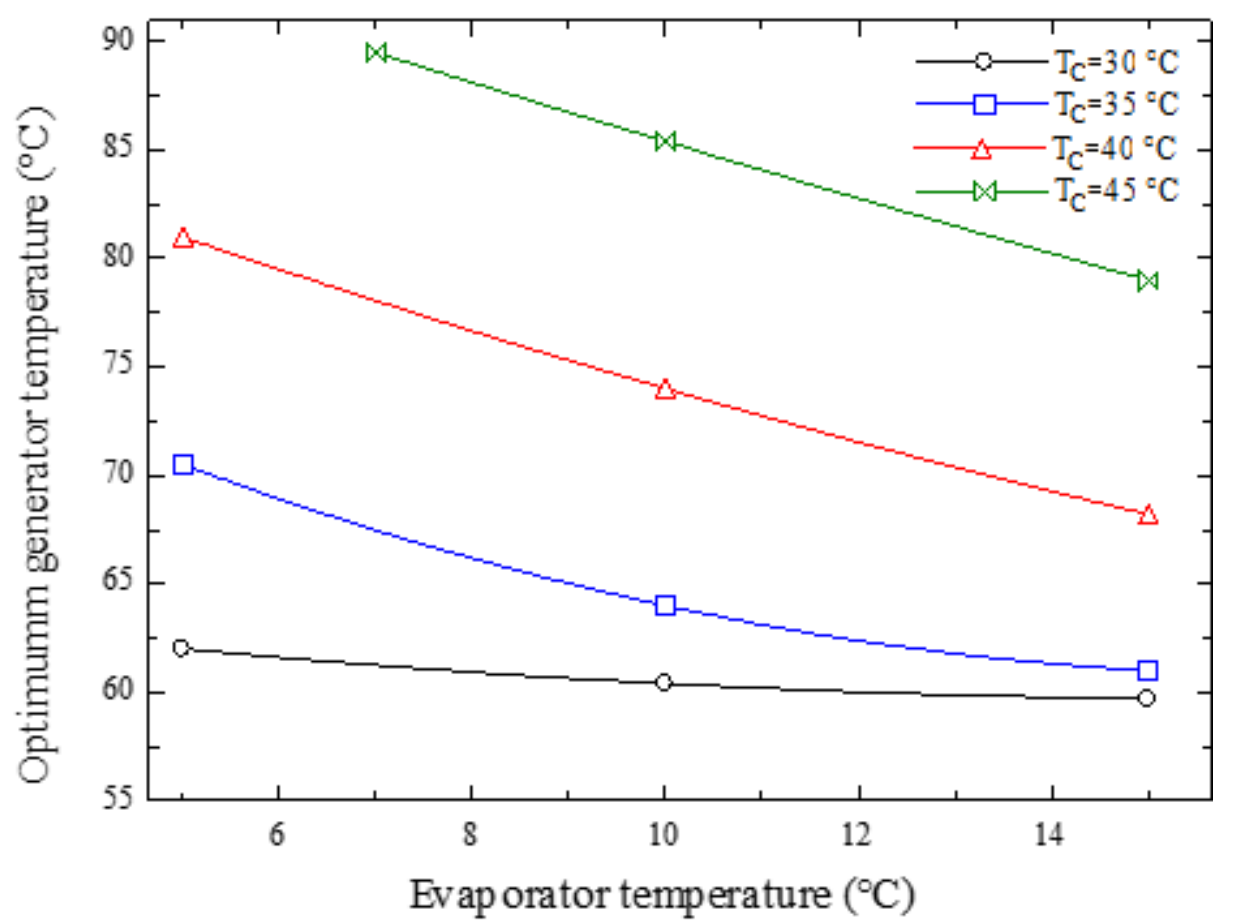

Figure 7. Optimum generator temperature corresponding to minimum exergy destruction against evaporator temperature at various condenser temperatures

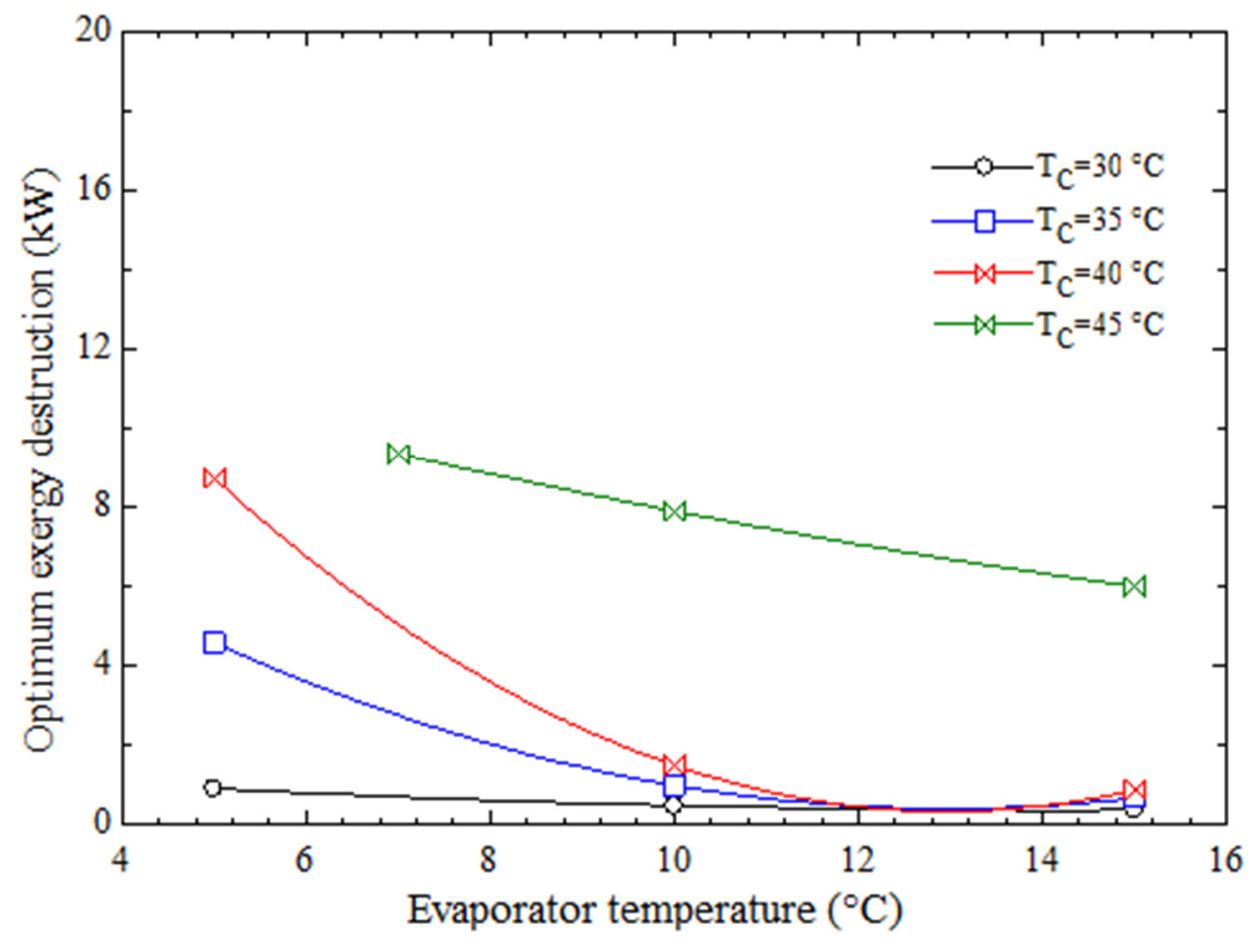

Figure 8. Variation of optimized exergy destruction with evaporator temperature for various condenser temperature.

that optimum generator temperature related to optimized (minimum) exergy destruction rate found lower than that for optimized (maximum) COP. Analytically it is lower by $4.4^{\circ} \mathrm{C}$.

\section{Optimum generator temperature}

In every considered case, optimized value has been determined by selecting maxima or minima point on each curve. Maxima point on each curve has been identified and on combining all maxima point from different curves at various condenser and evaporator temperatures, optimized COP curve is obtained in Figure 6. For optimized exergy destruction curve, minima point was considered as reference and rest of the procedure is same and depicted in Figure 8. Generator temperature corresponding to optimized COP and optimized exergy destruction rate has 


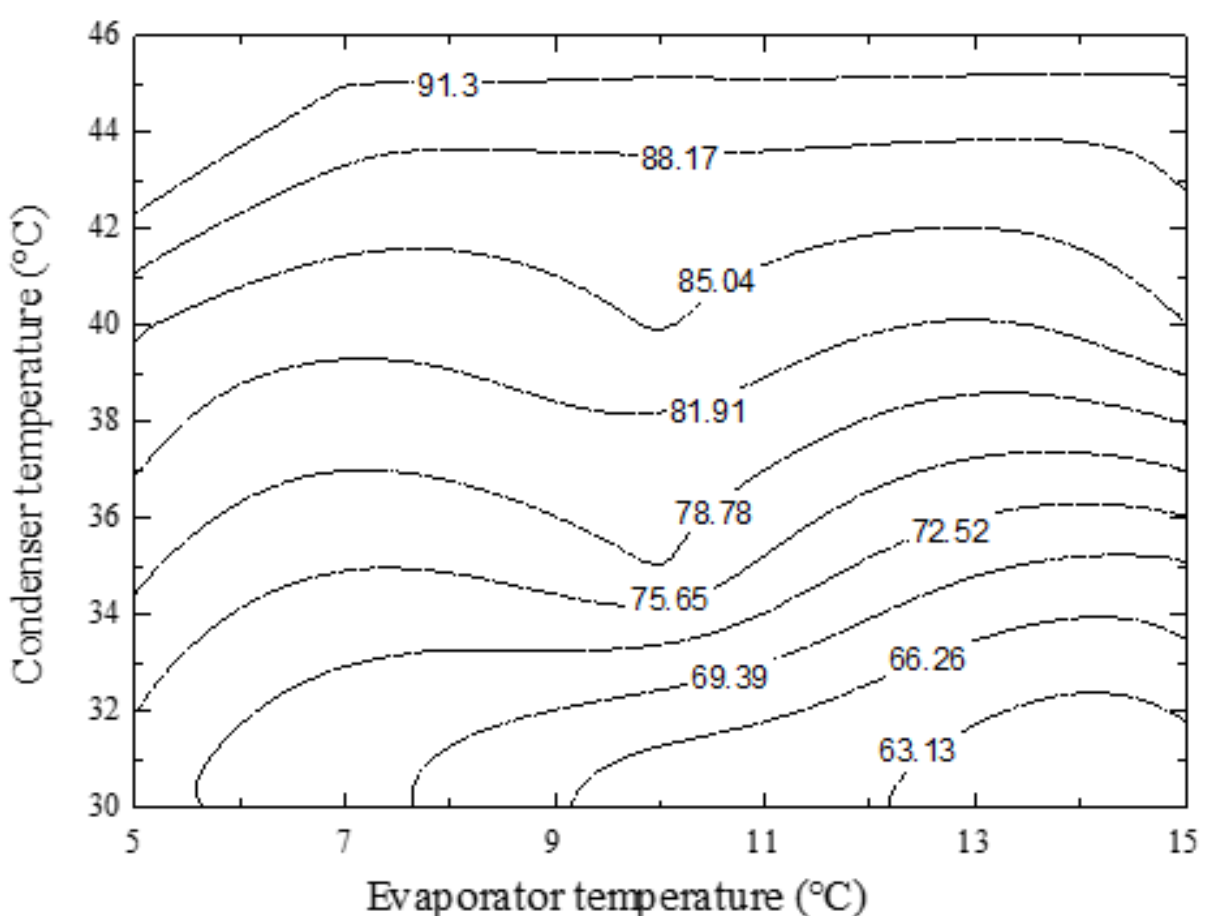

Figure 9. Contour of optimum generator temperature for optimized COP.

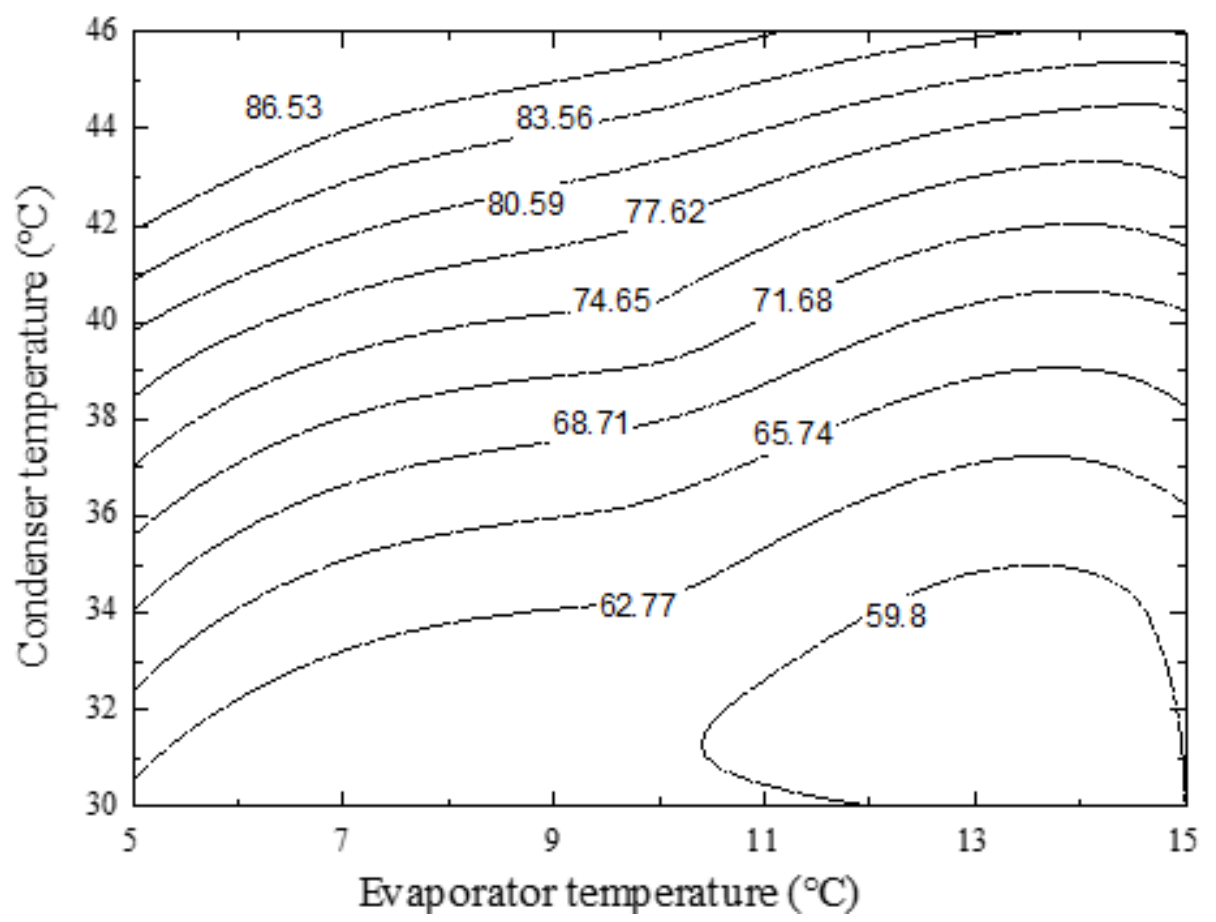

Figure 10. Contour of optimum generator temperature for optimized exergy destruction.

been found out. Optimum generator temperature corresponding to optimized COP and exergy destruction rate has been depicted in Figure 5 and 7 respectively.

Figure 5 illustrates the change of optimum generator temperature related to optimum COP for various evaporator and condenser temperatures. It is noticed that with increase in evaporator temperature, optimum generator temperature decreases while in contrast with increase in condenser temperature, it increases. It is found that negligible variation is observed for optimum generator temperature corresponding to maximum COP at higher condenser temperature. From Figure 5 it is found that optimum $\mathrm{T}_{\mathrm{G}}$ found as $91.3^{\circ} \mathrm{C}, 90.9^{\circ} \mathrm{C}$ and $90.7{ }^{\circ} \mathrm{C}$ for $\mathrm{T}_{\mathrm{C}}$ $=45^{\circ} \mathrm{C}$ and $\mathrm{T}_{\mathrm{C}}=7^{\circ} \mathrm{C}, \mathrm{T}_{\mathrm{E}}=10^{\circ} \mathrm{C}$ and $\mathrm{T}_{\mathrm{E}}=15^{\circ} \mathrm{C}$ respectively.

Figure 7 illustrates the change of optimum generator temperature related to optimum exergy destruction rate for various evaporator and condenser temperatures. It is obvious that with increase in evaporator temperature, temperature difference between reference ambient temperature and evaporator temperature decreases that causes lower entropy generation and exergy destruction in the system. Therefore, optimum generator temperature 
decreases with evaporator temperature. But simultaneously in contrast, on increasing the condenser temperature, temperature difference between water refrigerant and reference ambient temperature increases, hence raises exergy destruction of system.

It is inferred from Figure 6 that with increase in evaporator temperature optimized COP of system increases while in opposite it decreases with condenser temperature. Figure 8 depicts the effect of various condenser and evaporator temperature upon optimized exergy destruction rate. General conclusion form this figure is that optimized exergy destruction rate decreases with evaporator temperature and increases with condenser temperature. Through energy and exergy analysis of system, it is remarked that optimum generator temperature related to maximized COP and minimized exergy destruction rate is not identical. From this analysis it is identified that, optimization of generator temperature strongly depends upon various combination of evaporator and condenser temperature. Contour plots of optimum generator temperature for optimized COP and exergy destruction rate has been illustrated in Figure 9 and Figure 10 respectively. Overall result at different operating conditions is depicted in Table 1. In this table, cut-off temperature, optimum generator corresponding to first and second law perspective and maximum generator temperature has been stated.

\section{CONCLUSION}

The detailed thermodynamic optimization using energy and exergy methods for $\mathrm{LiCl}-\mathrm{H}_{2} \mathrm{O}$ absorption system has been studied in this case at different operating conditions of evaporator and condenser temperatures. Through thermodynamic analysis, it is concluded that optimum generator temperature by exergy based approach is $4.4 \mathrm{C}^{\circ}$ lower with respect to energy based approach. Both the optimum generator temperature corresponding to energy and exergy based methods increases with condenser temperature and decreases with evaporator temperature. Therefore, it is feasible to identify optimum generator temperature for different combination of condenser and evaporator temperatures. There is an increase of $85 \%$ in exergy destruction rate from its optimized value if system works at optimum generator temperature related to optimized COP while there is a decrement about $38 \%$ of COP compared to optimized COP if system works at optimum generator temperature related to optimized exergy destruction rate. Hence, exergy destruction rate is more sensitive to any change from optimum condition compared to COP. Therefore, exergy based approach should be selected and comparatively effective option for optimization of $\mathrm{LiCl}-\mathrm{H}_{2} \mathrm{O}$ VARS.

\section{REFERENCES}

Arora, A., \& Kaushik, S. C. (2009). Theoretical analysis of LiBr/H2O absorption refrigeration systems. International Journal of Energy Research, 33(15), 1321-1340.

Bolaji, B.O., \& Huan, Z. (2013). Ozone depletion and global warming: Case for the use of natural refrigerant- A review. Renewable and Sustainable energy reviens, 18, 49-54.

ElGhalban, A. R. (2002). Operational results of an intermittent absorption cooling unit. International journal of energy research, 26(9), 825-835.

Gebreslassie, B. H., Groll, E. A., \& Garimella, S. V. (2012). Multi-objective optimization of sustainable singleeffect water/Lithium Bromide absorption cycle. Renewable energy, 46, 100-110.

Gogoi, T. K., \& Konwar, D. (2016). Exergy analysis of a H 2 O-LiCl absorption refrigeration system with operating temperatures estimated through inverse analysis. Energy Conversion and Management, 110, 436-447.

Gommed, K., Grossman, G., \& Ziegler, F. (2004). Experimental investigation of a LiCl-water open absorption system for cooling and dehumidification. Transactions-american society of mechanical engineers journal of solar energy engineering, 126(2), 710-715.

Grover, G. S., Eisa, M. A. R., \& Holland, F. A. (1988). Thermodynamic design data for absorption heat pump systems operating on water-lithium chloride-part one. Cooling. Heat Recovery Systems and CHP, 8(1), 33-41

Gunhan, T., Ekren, O., Demir, V., Hepbasli, A., Erek, A., \& Sahin, A. S. (2014). Experimental exergetic performance evaluation of a novel solar assisted LiCl-H $2 \mathrm{O}$ absorption cooling system. Energy and Buildings, 68, 138-146.

Kaynakli, O., \& Yamankaradeniz, R. (2007). Thermodynamic analysis of absorption refrigeration system based on entropy generation. Current science, 92(4), 472-479.

Klein, S. A., \& Alvarado, F. L. (1992). EES: Engineering equation solver for the Microsoft Windows operating system. F-Chart Software.

Marcos, J. D., Izquierdo, M., \& Palacios, E. (2011). New method for COP optimization in water-and air-cooled single and double effect $\mathrm{LiBr}$-water absorption machines. International journal of refrigeration, 34(6), 1348-1359. 
Rubio-Maya, C., Pacheco-Ibarra, J. J., Belman-Flores, J. M., Galván-González, S. R., \& Mendoza-Covarrubias, C. (2012). NLP model of a LiBr-H 2 O absorption refrigeration system for the minimization of the annual operating cost. Applied Thermal Engineering, 37, 10-18.

Palacio R., Gonzales, R., \& Nebra, S. A. (2012). Exergy calculation of lithium bromide-water solution and its application in the exergetic evaluation of absorption refrigeration systems $\mathrm{LiBr}-\mathrm{H} 2 \mathrm{O}$. International Journal of Energy Research, 36(2), 166-181.

Saravanan, R., \& Maiya, M. P. (1998). Thermodynamic comparison of water-based working fluid combinations for a vapour absorption refrigeration system. Applied thermal engineering, 18(7), 553-568.

Samanta, S., \& Basu, D. N. (2016). Energy and Entropy-Based Optimization of a Single-Stage Water-Lithium Bromide Absorption Refrigeration System. Heat Transfer Engineering, 37(2), 232-241.

Saravanan, R., \& Maiya, M. P. (1998). Thermodynamic comparison of water-based working fluid combinations for a vapour absorption refrigeration system. Applied thermal engineering, 18(7), 553-568.

Srikhirin, P., Aphornratana, S., \& Chungpaibulpatana, S. (2001). A review of absorption refrigeration technologies. Renewable and sustainable energy reviews, 5(4), 343-372.

Won, S. H., \& Lee, W. Y. (1991). Thermodynamic design data for double effect absorption heat pump systems using water-lithium chloride-cooling. Heat Recovery Systems and CHP, 11(1), 41-48.

Wu, S., \& Eames, I. W. (2000). Innovations in vapour-absorption cycles. Applied Energy, 66(3), 251-266.

Yunus, A. C., \& Michael, A. B. (2006). Thermodynamics: An engineering approach. McGraw-Hill, New York. 